\title{
The Terminological Polyhedron in LGBTQ Terminology: Self-Naming as a Power to Empower in Knowledge Organization ${ }^{\dagger}$
}

\author{
D. Grant Campbell*, José Augusto Chaves Guimarães**, Fabio Assis Pinho***, \\ Daniel Martínez-Ávila**** and Francisco Arrais Nascimento***** \\ *University of Western Ontario, Canada, <gcampbel@uwo.ca> \\ UNESP - São Paulo State University, Brazil, \\ **<guima@marilia.unesp.br>,****<dmartinezavila@marilia.unesp.br>, \\ *****francisco.arrais.nascimento@gmail.com \\ ***Department of Information Science, Federal University of Pernambuco, Recife, Brazil, \\ <fabiopinho@ufpe.br>
}
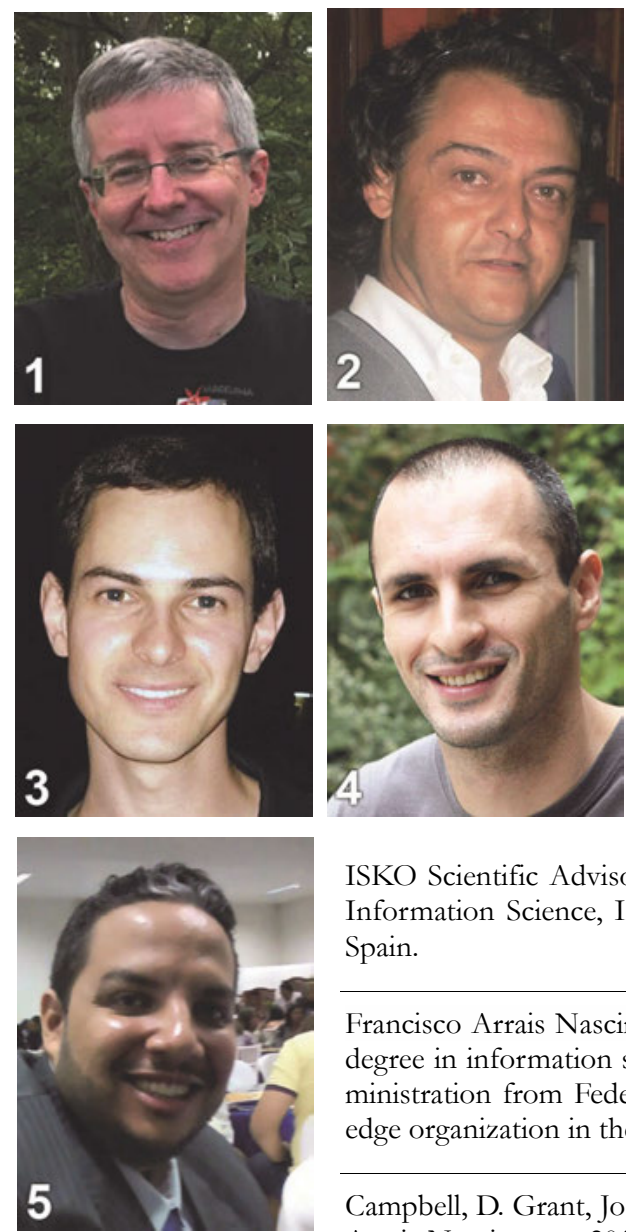
Science, São Paulo State University (UNESP), Marília, Brazil. He is a member of the ISKO Scientific Advisory Council. He also collaborates with the Satija Research Foundation for Library and Information Science, India, and the Institute for Gender Studies (IEG) at University Carlos III of Madrid, Spain.

Francisco Arrais Nascimento is a a PhD student at São Paulo State University (UNESP). He holds a master's degree in information science from Federal University of Pernambuco (UFPE) and a bachelor's degree in administration from Federal University of Ceará (UFC). He has experience in information science and knowledge organization in the areas of sexuality, document analysis and the thematic process of information.

Campbell, D. Grant, José Augusto Chaves Guimarães, Fabio Assis Pinho, Daniel Martínez-Ávila and Francisco Arrais Nascimento. 2017. "The Terminological Polyhedron in LGBTQ Terminology: Self-Naming as a Power to Empower in Knowledge Organization.” Knowledge Organization 44(8): 586-591. 29 references.

Abstract: This paper uses Hope Olson's concept of "the power to name" to explore the terminological practices of the LGBTQ community in the Cariri region of Brazil in the years between 2006 and 2013. LGBTQ communities can seize back the "power to name," traditionally exerted by a heteronormative society upon marginalized groups, by organizing their cultural and practical knowledge from 
D. G. Campbell, J. A. Ch. Guimarães, F. A. Pinho, D. Martínez-Ávila, F. A. Nascimento. The Terminological Polyhedron ...

within and by exercising the power to name themselves and their specific domains and cultural practices. The study showed that knowledge organization - the act of defining entities and categories and assigning specific names to them-is a gesture of self-empowerment on many different levels. The "power of self-naming" in this LGBTQ community is a polyhedron in which some facets are frequent, such as the power to empower or affirm an identity. On the one hand, the names and categories break through gender, geographical and temporal specificity to embrace terms, names, and idioms drawn from a range of different countries, traditions, languages, and time periods. On the other hand, these names and categories work to reinforce and affirm the geographical and cultural specificity of the Cariri region itself, embedding its pride and self-affirmation within the varied languages and heteronormative history of Portuguese colonization in that region. In selecting terms and categories to name, organize, and celebrate their identities, the LGBTQ people of Cariri have taken the power to name: not as information intermediaries striving for objectivity and neutrality but as committed members of a marginalized but vital community.

Received: 23 October 2017; Accepted 25 October 2017

Keywords: terms, knowledge organization, power, lgbtq

† Paper presented at the ISKO-Canada/US, Sixth North American Symposium on Knowledge Organization: Visualizing Knowledge Organization: Bringing Focus to Abstract Realities, June 15-17, 2017, Champaign, IL, USA.

\subsection{Introduction}

The need for an ethical commitment in knowledge representation is a recurrent concern in the literature of library and information science (LIS)(Berman 1993; Beghtol 2002 and 2005; Fernández Molina and Guimarães 2002; García Gutiérrez 2002; Guimarães et al. 2008; Hudon 1997; Olson 1998 and 2002; Pinho 2010, among others) on aspects related to prejudices, antipathies, proselytism, euphemism, cultural warrant, cultural hospitality, literality, and political correctness, among others. Considering this stream of publications, this paper explores Olson's notion of "power to name" (2002), originally conceived as a power that the librarian has when creating surrogates for documents in knowledge organization systems (KOSs) and adding another dimension, the "power of selfnaming," exerted when specific and marginalized communities decide to represent specific subjects using new terms that can serve as a communication code among the members of the community, also including other purposes such as identification and protection. One example of this is the LGBT (lesbian, gay, bisexual and transgender) environment, whose distinct features lead not only to a richness of specialty vocabularies but also to a tension between aboutness and meaning as studied by Campbell (2000). In this sense, we explore the terminological practices within LGBTQ communities (lesbian, gay, bisexual, transgender and questioning) in the Cariri region (a region whose recent growth and development, as Leite Júnior and Nascimento 2017 point out, has been based on religious imagery such as Beata Maria Magdalena do Espírito Santo de Araújo and Father Cicero Romão Batista and the multicultural influence of the Portuguese colonizers, native indigenous populations, and the African slaves) in the years between 2006 and 2013, based upon an ongoing study of the knowledge organiza- tion dimensions of the terminological patterns of LGBTQ people from that region (Guimarães, Nascimento, and Pinho 2016).

The "power to name" has been traditionally exerted by a heteronormative society upon marginalized groups. This research analyzes how LGBTQ communities seize that power back by organizing their cultural and practical knowledge from within and by exercising the power to name themselves and their specific domains and cultural practices. In this sense, queer research can be characterized as a contingent, multiple, and unstable subject (Browne and Nash 2010) that is always struggling between the need for recognition and the avoidance of essentialism. Queer scholars also claim (Browne and Nash 2010, 7-8) that "what we mean by queer, we argue, is and should remain unclear, fluid and multiple." Eventual mutations and incorporation of new terms is a strategy of survival of the community. Terms must be understood and shared by the community as a code, but, at the same, time they must be overcome when the risk of essentialism is near.

LGBTQ vocabularies constitute specialized languages that include rich figures of speech and that work on multiple levels (in a tension between the power to evidence and the power to hide). These levels of meaning allow speakers both to limit the understanding of their vocabulary to their members and to revel in the richness of imagery that populates the LGBTQ universe (Pinho and Guimarães 2012). The richness of the imagery of a given vocabulary can be evidenced especially by the presence of a vivid and innovative metaphorical dimension (Konrad 1958; Lakoff and Johnson 1980; Black 1981; Pinho 2010).

The study of these metaphors inevitably involves consideration of time. LGBTQ terminology is ever-shifting and heavily relies on metaphors, metonyms, metaphtonymies (Bustos 2010; Goossens 1990), and other figures 
of speech that have historical connotations and add even more complexity for knowledge organization processes.

In addition to this temporal variation of terms (an aspect that has been recently studied, for instance, in Fox 2016), this paper also suggests another axis for the analysis of the complexity and strategies of the LGBTQ and queer communities' power to name, as proposed by Guimarães (2017) for a glocal (global + local) approach: space. Although many of the terms that are used by these groups are imported and adapted from English, and more specifically from the United States (Bustos 2010; Trim 2007), local communities also propose regional variations and terms, using metaphors and other figures of speech too, as a reflection of their mundane reality and as a partial reinforcement of their cultural identity. This second axis, space, is another dimension that methodologically opens many possibilities for the study of and research into the LGBTQ's organization of knowledge.

In this paper, we furnish and analyze an example of how an LGBTQ vocabulary can be committed to its cultural background and, at the same time, to the international terminological configuration of the field.

\subsection{Objective}

The paper aims to verify to what extent this "power of self-naming" is present in this community as well as the categories that are used in the knowledge representation process that this power entails.

\subsection{Methodology}

The Cariri region, originally occupied by the Kariri Indian tribe, is located in the south of Ceará State in Northeastern Brazil and was the destination of many migratory cycles of pilgrims. Its cultural identity has, therefore, been shaped since early times by religious and heteronormative concepts; concepts which gave no place to alternative sexualities. The records and experiences of LGBTQ people living in this region have historically been marginalized, forgotten, or excluded from the history of this region. Nonetheless, LGBTQ people are there, and in the late 1990s, they found their voice and began to advocate for minority rights. In the years that followed, their actions and, equally important, their language, was captured in the proceedings of various non-governmental organizations (NGOs).

This paper is based on a documentary analysis of twenty-five meeting minutes published between 2006 and 2013 by two NGOs (non-governmental organizations): Grupo de Apoio a Livre Orientação Sexual (Supporting Group to the Free Sexual Orientation, GALOSC) and Associação de Apoio, Defesa e Cidadania dos Homossexuais
(Association for the Support, Protection and Citizenship of Homosexuals, AADECHO). The minutes are usually composed of the following structure: 1) title; 2) opening; 3) identification of the members present; 4) agenda; and, 5) closing. The methodological procedures included the following steps (Nascimento 2015): a) domain analysis (Hjørland and Albrechtsen 1995; Hjørland 1997 and 2002; Tennis 2003 and 2012; Smiraglia 2013) in order to understand the extension and scope of the domain to analyze according to the discourse community; b) selection and reading of the minutes; c) identification and extraction of metaphorical terms; and, d) categorization of the terms using content analysis (Bardin 1989). For the step of identification and extraction of metaphorical terms, we used a technique of continuous reading of empirical materiality in order to try to grasp the meanings that have not been noticed or not said. This phase of continuous readings allows the analyst to find repetitive words and phrases that may represent situations more or less coherent and of similar meaning, metaphors which may involve specific images or words with particular meanings.

\subsection{Results and discussion}

A study of these minutes and an extraction of the relevant terms produced eight hundred fifteen metaphorical terms that allow the definition of three major categories: women's names (e.g., Hebe Camargo, Greta Garbo, Emma Thompson, Deborah Kerr, Uma Thurman, Watusi, etc.); body parts (e.g., suitcase, velcro); and, actions (e.g., free the chicken, behave like an Egyptian, break the porcelain, to be beige). Within these categories, two sets of contrasts emerged. First, the variety of metaphors serves both to hide and to reveal. The use of euphemisms for body parts and sexual acts, on the one hand, enables a marginalized community to have its own language, with terms that those outside the community would not understand. On the other hand, the terms provide a rich and variegated means of identifying, and celebrating body parts and sexual acts that are often silenced through overt censorship or through self-censorship. That is the case of imaginative and inventive euphemisms to identify and celebrate body parts and sexual acts that are often silenced.

The naming patterns within LGBTQ communities in the Cariri region suggest that knowledge organization - the act of defining entities and categories and assigning specific names to them-is a gesture of self-empowerment on many different levels. The study showed that the "power of self-naming" in this LGBTQ community is a polyhedron in which various facets appear. Three facets appeared with particular frequency: 
- the power to empower/to affirm an identity. Examples include: Watusi (reference to a very famous Brazilian actress/singer, member of the Moulin Rouge's cast); Wonder woman (powerful guy); free the chicken (for coming out of the closet); Alice (a gay dreamer);

- the power to ironize/to criticize. Examples include: Nefertite (a very old gay who keeps an aura of mystery); truck driver, diesel, tank panzer (a lesbian with very masculine manners); dragon (very ugly person); bread with egg (very poor gay, named after the cheapest sandwich in Brazil); Greta (a shy and mysterious gay, in allusion to Greta Garbo's personality); social security (night club whose customers are usually elderly people); Banho de Cleópatra (activities that involve copious amounts of a substance reminiscent of Cleopatra's fabled baths of milk); and,

- the power to self-protect. Examples include: Alibã/ Aliban (police); Papapum (onomatopoeic reference to revolver, gun); Philips (for civil police car); Africa (something hard, painful, referencing to the African slaves, and more).

This empowerment follows two surprisingly different trajectories. On the one hand, the names and categories break through gender, geographical, and temporal specificity to embrace terms, names, and idioms drawn from a range of different countries, different traditions, different languages, and different time periods. The widespread use of female names, in particular, draws from a richly varied set of times and places and cultures both within and beyond Brazilian mainstream culture. Many of the terms derive from French and English traditions, including popular gay linguistic hybrids such as "lesbian chic" or Fashion "dénécessaire."

On the other hand, these names and categories work to reinforce and affirm the geographical and cultural specificity of the Cariri region itself, embedding its pride and selfaffirmation within the diverse languages and heteronormative history of Portuguese colonization in that region. The language of these minutes is full of words, not only from Portuguese but also from English, German, French, and African languages such as bajubá (e.g., truck driver-a very masculinized lesbian; lipstick lesbian-a very feminine lesbian; tank panzer-a very masculinized lesbian; bas fond-marginalized social classes; beige - to be surprised; Ajeum-food, Guanto-condom, Ocani-male body parts). These different positions can also be observed in the use of imported terms (e.g., bear) and the construction of regional expressions (e.g., "free the chicken," coming out of the closet).

It is also possible to observe a richness in terms of the construction of the metaphors, by means of onomatopoeias (e.g., Uma Thurman-group of gays or "uma turma" in Portuguese or Emma Thompson-hematoma); double meaning methaphors (e.g., break the porcelain-affective relationship between two gays or a hard discussion between two gays); or neologisms (e.g., pitt boy-aggressive homophobic man-from pit bull).

\subsection{Implications for practice}

For professionals in knowledge organization, the implications of this study are ambiguous: to what extent should the naming practices of marginalized communities be incorporated into standard retrieval tools and knowledge organization structures? On the one hand, keeping up with the constantly shifting terminology within marginalized communities is difficult, expensive, time-consuming, and ultimately futile. Even as indexers discover fresh concepts and terms and lead-in terms, the community abandons them for even newer terms, unknown to established institutions and law-enforcement bodies. On the other hand, the richness of these terms suggests a valuable opportunity; the opportunity to ground subject languages within the unique vitality of specific temporal and geographical regions. This opportunity should not be wasted.

Empowerment: Terms of empowerment are clearly the most important for $\mathrm{KO}$ professionals, since they indicate the terms most appropriate for inclusion in standard tools, either as preferred terms or as lead-in terms (e.g., coming out UF freeing the chicken). This is important, because, as observed by Pinho (2010), these terms are beginning to appear as keywords in the scientific literature.

Irony and criticism: The ironic appropriation of terms for ludicrous or satiric effect often requires a knowledge of the specific context in order to be either informative or effective. While they are unlikely to serve much use in the context of a standard KO tool, professionals may find lists of such terms useful in the process of document analysis for indexing purposes. In addition, some may serve a useful collocating function; both "Banho de Cleopatra" and "Nefertiti," for instance, allude to a fascination in various gay cultures with the extravagances of Egypt in popular entertainment and could provide a meaningful means of access to plays like Michel Tremblay's Hosanna. It is important to consider this aspect during the indexing of the document. For example, the information on the back cover of a book saying: "In this play, a young man is humiliated at a party where he dresses up as Elizabeth Taylor in Cleopatra," could be an indication of the subject gay men. 
Self-protection: We anticipate that the LGBTQ community's terms of self-protection will continue to be their own, as long as its members feel the need to resort to protective measures within their own community. Such terms will mutate quickly, to remain unknown outside the community. For such terms, the professional $\mathrm{KO}$ community's role will primarily be an historical one: preserving the record of such terms, to remind later members of the community of that community's history. Terms that provide protection would be: Ajé (a person who is fake, bad, lousy); Alibã/Aliban (police); Alibete (robbery); Gambé (police officer); Black magic (a big danger); Magic (a circumstance, state or situation that foretells something bad to someone or something); Malassombro (strange people or situations that cause certain fears and/or have bad energy); Mortt (state of mind in which anger is exacerbated; goat (irritation because of a person, something or a situation); Papapum (revolver); Philips (undercover police car); Rotten (a bad thing, person or situation); Aunt Cleide (police truck); I'll grab her MUCO (I'll fall for it); and Yvone (fake female friend), among others.

\subsection{Conclusion}

In selecting terms and categories to name, organize, and celebrate their identities, the LGBTQ communities of Cariri have taken the power to name; not as information intermediaries striving for objectivity and neutrality but as committed members of a marginalized but vital community. In the years of growing liberation and selfaffirmation, the people represented in these documents wielded their power to define themselves; in so doing, they created a metaphorical system of great variety and diversity, which both broke through limitations of their specific time and place and, paradoxically, drew on that specific time and place to create a vocabulary, and a world view, that belongs uniquely to themselves.

Considering this paper as an example of a terminological approach to domain analysis, as proposed by Hjørland (2002), we conclude that the "power to name" goes beyond the power of the librarian to assign terms and also reaches the "power to self-name," as LGBT terminology is polyhedrically constructed in a space/time dimension that oscillates between self-protection and selfempowerment.

\section{References}

Bardin, Laurence. 1989. L'analyse de contenu. 5th ed. Le psychologue 69. Paris: Presses universitaires de France.
Beghtol, Clare. 2002. “A Proposed Ethical Warrant for Global Knowledge Representation and Organization Systems." Journal of Documentation 58:507-32.

Beghtol, Clare. 2005. "Ethical Decision-Making for Knowledge Representation and Organization Systems for Global Use." Journal of the American Society for Information Science and Technology 56:903-12.

Berman, Sanford. 1993. Prejudices and Antipathies: A Tract on The LC Subject Heads Concerning People. Jefferson, NC: McFarland.

Black, Max. 1981. Models and Metaphors: Studies in Language and Philosophy. Ithaca, NY: Cornell University Press.

Browne, Kath, and Catherine J. Nash, eds. 2010. Queer Methods and Methodologies: Intersecting Queer Theories and Social Science Research. Farnham, UK: Ashgate.

Bustos Plaza, Alberto. 2010. "Nombrar lo innombrable: La autorrepresentación lingüística de grupos gays no convencionales". In Historia y pensamiento en torno al género, ed. Montserrat Huguet, and Carmen González Marín. Madrid: Dykinson, 243-66.

Campbell, Grant. 2000. "Queer Theory and the Creation of Contextual Subject Access Tools for Gay and Lesbian Communities.” Knowledge Organization 27:122-31.

Fernández-Molina, Juan Carlos and José Augusto Chaves Guimarães. 2002. "Ethical Aspects of Knowledge Organization and Representation in the Digital Environment: Their Articulation in Professional Codes of Ethics." In Challenges in Knowledge Representation and Organization for the 21st Century: Integration of Knowledge Across Boundaries; Proceedings of the Seventh International ISKO Conference, 10-13 July 2002 Granada, Spain, ed. María José López-Huertas, and Francisco J. MunozFérnandez. Advances in Knowledge Organization 8. Würzburg: Ergon, 487-92.

Fox, Melodie J. 2016. "Subjects in Doubt: The Ontogeny of Intersex in the Dewey Decimal Classification." Knowledge Organization 43:581-93.

García-Gutiérrez, Antonio. 2002. "Knowledge Organization from a 'Culture of The Border:' Towards a Transcultural Ethics of Mediation." In Challenges in Knowledge Representation and Organization for the 21st Century: Integration of Knowledge Across Boundaries; Proceedings of the Seventh International ISKO Conference, 10-13 July 2002 Granada, Spain, ed. María José López-Huertas, and Francisco J. Munoz-Férnandez. Advances in Knowledge Organization 8. Würzburg: Ergon, 516-22.

Goossens, Louis. 1990. "Metaphtonymy: The Interaction of Metaphor and Metonymy in Expressions for Linguistic Action." Cognitive Linguistics 1: 323-40.

Guimarães, José Augusto Chaves, Juan Carlos FernándezMolina, Fabio Assis Pinho, and Suellen de Oliveira Milani. 2008. "Ethics in the Knowledge Organization Environment: An Overview of Values and Problems 
in The LIS Literature." In Cultural and Identity in Knowledge Organization: Proceedings of the Tenth International ISKO Conference 5-8 August 2008 Montréal, Canada, ed. Clément Arsenault, and Joseph T. Tennis. Advances in Knowledge Organization 11. Würzburg: Ergon, 340-6.

Guimarães, José Augusto Chaves, Francisco Arrais Nascimento, and Fabio Assis Pinho. 2016. "The Metaphorical Dimension of LGBT Information: Challenges for Its Subject Representation.” Paper presented at the IFLA-LGBTQ Users SIG Satellite Meeting 'DocuQueer: Preserving Community Through Collaborative Collections," Chicago, IL, August 10.

Hjørland, Birger. 1997. Information Seeking and Subject Representation: An Activity Theoretical Approach to Information Science. New Directions in Information Management 34. Westport, CT: Greenwood Press.

Hjørland, Birger. 2002. "Domain Analysis in Information Science: Eleven Approaches; Traditional as Well As Innovative." Journal of Documentation 58:422-62.

Hjørland, Birger, and Hanne Albrechtsen. 1995. "Toward a New Horizon in Information Science: DomainAnalysis." Journal of the American Society for Information Science 46:400-25.

Hudon, Michèle. 1997. "Multilingual Thesaurus Construction: Integrating the Views of Different Cultures in One Gateway to Knowledge and Concepts." Knowledge Organization 24:84-91.

Konrad, Hedwig. 1958. Étude sur la métaphore. Paris: J. Vrin.

Lakoff, George, and Mark Johnson. 1980. Metaphors We Live By. Chicago: University of Chicago Press.

Leite Júnior, Francisco Francinete, and Francisco Arrais Nascimento. 2017. “'Também sou teu povo:' As interpelações sagradas/profanes nos contextos de traves- tilidades na cidade Juazeiro do Norte, CE." Revista de Audiovisual Sala 206 6:205-32.

Nascimento, Francisco Arrais. 2015. "Memória da militância: A contribuição da Organização do Conhecimento para a reconstrução da memória do movimento LGBT da região do Cariri cearense." Master's thesis, Universidade Federal de Pernambuco.

Olson, Hope A. 1998. “Mapping beyond Dewey's Boundaries: Constructing Classificatory Space for Marginalized Knowledge Domains." Library Trends 47:233-54.

Olson, Hope A. 2002. The Power to Name: Locating the Limits of Subject Representation in Libraries. Dordrecht: Kluwer Academic.

Pinho, Fabio Assis. 2010. "Aspectos éticos em representação do conhecimento em temáticas relativas à homossexualidade masculina: Uma análise da precisão em linguagens de indexação brasileiras." PhD diss., Universidade Estadual Paulista (UNESP).

Smiraglia, Richard P. 2012. "Epistemology of Domain Analysis." In Cultural Frames of Knowledge, ed. Hur-Li Lee, and Richard P. Smiraglia. Wurzburg: Ergon, 11124.

Tennis, Joseph T. 2003. “Two Axes of Domains for Domain Analysis.” Knowledge Organization 30:191-5.

Tennis, Joseph T. 2012. "A Convenient Verisimilitude or Oppressive Internalization?: Characterizing the Ethical Arguments Surrounding Hierarchical Structures in Knowledge Organization Systems." Knowledge Organization 39:394-7.

Trim, Richard. 2007. Metaphor Networks: The Comparative Evolution of Figurative Language. New York: Palgrave Macmillan. 